\title{
Improved in-hospital outcome for radial access in a large contemporary cohort of primary percutaneous coronary intervention
}

\author{
Matthias Hasun ${ }^{1 \#}$, Jakob Dörler ${ }^{2 \#}$, Hannes F. Alber ${ }^{3}$, Axel Bauer ${ }^{2}$, Rudolf Berger ${ }^{4}$, Günter Christ ${ }^{5}$, \\ Matthias Frick ${ }^{6}$, Uta C. Hoppe ${ }^{7}$, Kurt Huber ${ }^{8}$, Gudrun Lamm ${ }^{9}$, Elisabeth Laßnig ${ }^{10}$, Dirk von Lewinski ${ }^{11}$, \\ Anna Rab ${ }^{12}$, Franz X. Roithinger ${ }^{13}$, Herwig Schuchlenz ${ }^{14}$, Peter Siostrzonek ${ }^{15}$, Johann Sipötz ${ }^{16}$, \\ Thomas Stefenelli ${ }^{17}$, Clemens Steinwender ${ }^{18}$, Michael Edlinger ${ }^{19,20}$, Franz Weidinger $^{1}$; \\ for the Austrian Acute PCI Investigators*
}

${ }^{1}$ 2nd Medical Department with Cardiology and Intensive Care Medicine, KA Rudolfstiftung, Vienna, Austria; ${ }^{2}$ Department of Internal Medicine III, Cardiology and Angiology, Medical University Innsbruck, Innsbruck, Austria; ${ }^{3}$ Department of Internal Medicine and Cardiology, Klinikum Klagenfurt am Wörthersee, Klagenfurt, Austria; ${ }^{4}$ Department of Internal Medicine I, Cardiology and Nephrology, Krankenhaus der Barmherzigen Brüder Eisenstadt, Eisenstadt, Austria; ${ }^{5} 5$ th Medical Department with Cardiology, Sozialmedizinisches Zentrum Süd - Kaiser Franz Josef Hospital, Vienna, Austria; ${ }^{6} 1$ st Department of Internal Medicine, Landeskrankenhaus Feldkirch, Feldkirch, Austria; ${ }^{7}$ Department of Internal Medicine II, Paracelsus Medical University Salzburg, Salzburg, Austria; ${ }^{8}$ rd Department of Internal Medicine, Cardiology and Intensive Care Medicine, Wilhelminenspital, and Medical School, Sigmund Freud University, Vienna, Austria; ${ }^{9}$ Department of Internal Medicine III, Universitätsklinikum St. Pölten, St. Pölten, Austria; ${ }^{10}$ Department of Internal Medicine II, Cardiology and Intensive Care Medicine, Klinikum Wels-Grieskirchen, Wels, Austria; ${ }^{11}$ Department of Internal Medicine, Cardiology, Medical University Graz, Graz, Austria; ${ }^{12}$ Department for Internal Medicine, Landeskrankenhaus Villach, Villach, Austria; ${ }^{13}$ Department of Internal Medicine, Cardiology and Nephrology, Landesklinikum Wiener Neustadt, Wiener Neustadt, Austria; ${ }^{14}$ Department of Internal Medicine, Cardiology and Intensive Care Medicine, Landeskrankenhaus Graz West, Graz, Austria; ${ }^{15}$ Department of Internal Medicine II - Cardiology, Ordensklinikum Linz Barmherzige Schwestern, Linz, Austria; ${ }^{16} 2 \mathrm{nd}$ Department of Internal Medicine, Hanusch Hospital, Vienna, Austria; ${ }^{17}$ Department of Internal Medicine I, Sozialmedizinisches Zentrum Ost - Donauspital, Vienna, Austria; ${ }^{18}$ Department of Internal Medicine I, Cardiology and Internal Intensive Medicine, Kepler Universitätsklinikum, Linz, Austria; ${ }^{19}$ Department of Medical Statistics, Informatics, and Health Economics, Medical University Innsbruck, Innsbruck, Austria; ${ }^{20}$ Department of Development and Regeneration, KU Leuven, Belgium

* Collaborators: M. Grund, J. Kammler, D. Hrncic (Department of Internal Medicine I, Cardiology and Internal Intensive Medicine, Kepler Universitätsklinikum Linz); A. Winter, E. Zeindlhofer (Department of Internal Medicine II - Cardiology, Ordensklinikum Linz Barmherzige Schwestern); R. Binder, E. Maurer (Department of Internal Medicine II, Cardiology and Intensive Care Medicine, Klinikum Wels-Grieskirchen); M. Juhasz, J. Rieschl (Department of Internal Medicine I, Cardiology and Nephrology, Krankenhaus der Barmherzigen Brüder Eisenstadt); G. Zenker, F. Zenker (Department of Internal Medicine, Landeskrankenhaus Bruck/Mur); W. Weihs, S. Harb (Department of Internal Medicine, Cardiology and Intensive Care Medicine, Landeskrankenhaus Graz West); G. Toth-Gayor, M. Sacherer, M. Wallner (Department of Internal Medicine, Cardiology, Medical University Graz); O. Pachinger (Department of Internal Medicine III, Cardiology and Angiology, Medical University Innsbruck); L. Kaltenbach, H. Ulmer (Department of Medical Statistics, Informatics, and Health Economics, Medical University Innsbruck); G. Fleischmann, T. Ovsenk. (Department for Internal Medicine, Landeskrankenhaus Villach); K. Laubreiter, J. Brandl (Department of Internal Medicine and Cardiology, Klinikum Klagenfurt am Wörthersee); M. Hammerer, W. Wintersteller (Department of Internal Medicine II, Paracelsus Medical University Salzburg); T. Banerjee, M. Walter ( $1^{\text {st }}$ Department of Internal Medicine, Landeskrankenhaus Feldkirch); R. Hoeppel, A. Dalos (Department of Medicine, Landeskrankenhaus Mödling); L. Fiedler, T. Gremmel (Department of Internal Medicine, Cardiology and Nephrology, Landesklinikum Wiener Neustadt); A. Podczeck-Schweighofer ( $5^{\text {th }}$ Medical Department with Cardiology, Sozialmedizinisches Zentrum Süd, Vienna); A. Auinger, P. Hasslinger (Department of Internal Medicine I, Sozialmedizinisches Zentrum Ost, Vienna); A. Geppert, E. Wessely, P. Smetana $\left(3^{\text {rd }}\right.$ Department of Internal Medicine, Cardiology and Intensive Care Medicine, Wilhelminenspital, Vienna); M. Winkler, I. Jukic (Department of Internal Medicine, Hanusch Hospital, Vienna); G. Delle Karth (Department of Cardiology, Krankenhaus Nord, Vienna); M. Derntl, A. Noorian, WB. Winkler (2 ${ }^{\text {nd }}$ Medical Department with Cardiology and Intensive Care Medicine, KA Rudolfstiftung, Vienna). 
Contributions: (I) Conception and design: M Hasun, J Dörler, M Edlinger, F Weidinger; (II) Administrative support: M Hasun, J Dörler, M Edlinger, F Weidinger; (III) Provision of study materials or patients: All authors; (IV) Collection and assembly of data: All authors; (V) Data analysis and interpretation: M Hasun, J Dörler, M Edlinger, F Weidinger; (VI) Manuscript writing: All authors; (VII) Final approval of manuscript: All authors.

\#These authors contributed equally to this work.

Correspondence to: Franz Weidinger, MD. $2^{\text {nd }}$ Medical Department with Cardiology and Intensive Care Medicine, KA Rudolfstiftung, Juchgasse 25, 1030 Vienna, Austria. Email: franz.weidinger@wienkav.at; Michael Edlinger, PhD. Department of Medical Statistics, Informatics, and Health Economics, Medical University Innsbruck, Austria; Department of Development and Regeneration, KU Leuven, Belgium. Email: Michael.Edlinger@i-med.ac.at.

Background: Randomised controlled trials have shown diverse results for radial access in patients undergoing primary percutaneous coronary intervention (PPCI). Moreover, it is questionable whether radial access improves outcome in patients with cardiogenic shock undergoing PPCI. We aimed to investigate the outcome according to access site in patients with or without cardiogenic shock, in daily clinical practice.

Methods: For the present analysis we included 9,980 patients undergoing PPCI between 2012 and 2018, registered in the multi-centre, nationwide registry on PCI for myocardial infarction (MI). In-hospital mortality, major adverse cardiovascular events (MACE), and net adverse clinical events (NACE) until discharge were compared between 4,498 patients with radial (45\%) and 5,482 patients with femoral (55\%) access.

Results: Radial compared to femoral access was associated with lower in-hospital mortality (3.5\% vs. 7.7\%; $\mathrm{P}<0.01)$. Multivariable logistic regression analysis confirmed reduced in-hospital mortality [odds ratio (OR) $0.57,95 \%$ confidence interval (CI): 0.43 to 0.75 ]. Furthermore, MACE (OR 0.60, 95\% CI: 0.47 to 0.78 ) as well as NACE (OR 0.59, 95\% CI: 0.46 to 0.75 ) occurred less frequently in patients with radial access. Interaction analysis with cardiogenic shock showed an effect modification, resulting in lower mortality in PCI via radial access in patients without, but no difference in those with cardiogenic shock (OR 1.78, 95\% CI: 1.07 to 2.96$)$.

Conclusions: Radial access for patients with acute MI undergoing PPCI is associated with improved survival in a large contemporary cohort of daily practice. However, this beneficial effect is restricted to hemodynamically stable patients.

Keywords: Primary percutaneous coronary intervention (PPCI); registry; radial access; cardiogenic shock; outcome

Submitted Dec 04, 2020. Accepted for publication Mar 28, 2021.

doi: $10.21037 / \mathrm{cdt}-20-977$

View this article at: http://dx.doi.org/10.21037/cdt-20-977

\section{Introduction}

The gold standard reperfusion therapy for patients with ST elevation myocardial infarction (STEMI) is primary percutaneous coronary intervention (PPCI), both with and without cardiogenic shock (CS) (1). Transradial access (TRA) for PCI has become the default access for PCI in many centres over the last years. It has been shown that TRA is associated with reduced vascular access complications, including protocol-defined bleeding, compared with transfemoral access (TFA) in acute coronary syndrome (2-6). However, recent trials have shown controversial results of
TRA on mortality. A lower mortality was found for TRA in RIVAL and RIFLE STEACS $(5,7)$, whereas in the STEMI subgroup of MATRIX access and the recent Canadian SAFARI trial, TRA did not result in reduced mortality compared to TFA $(6,8)$. Moreover, most of these trials completely excluded all or included only small subgroups of patients with CS. Noteworthy, even experienced TRA operators frequently treat hemodynamically unstable patients by TFA $(2-6,8)$. We therefore aimed to investigate the effect size of the outcome according to access site in a large contemporary cohort of STEMI patients, both with and 
without CS, undergoing PPCI.

We present the following article in accordance with the STROBE reporting checklist (available at http://dx.doi. org/10.21037/cdt-20-977).

\section{Methods}

The present analysis was performed in patients enrolled in the Austrian Acute PCI Registry (AAPCI), a prospective, multi-centre registry implemented 2005 by the Austrian Society of Cardiology. Most applicable PPCI-centres participated, covering the main part of the country. Details of the AAPCI Registry data have been published before $(9,10)$. The data was handled by the Department of Medical Statistics, Informatics, and Health Economics, Medical University, Innsbruck.

All consecutive patients entering a participating centre less than 24 hours after symptom onset and considered for PPCI for STEMI reperfusion, from January 2012 until December 2018, were included. Routine documentation of the patients' history and all events during the intervention and index hospitalisation was performed.

We classified the patients, according to the initial choice of access site for PPCI, into two groups: those treated via TRA and those via TFA. In the present analysis inhospital mortality from all causes was the primary outcome of interest. As for the secondary endpoints, these included major adverse cardiovascular events (MACE: death, reinfarction, or stroke) and net adverse clinical events [NACE: MACE or thrombolysis in myocardial infarction (TIMI) non-CABG-related major bleeding] until discharge.

Data definitions followed the Cardiology Audit and Registration Data Standards (CARDS) (11). We diagnosed STEMI in the presence of persistent angina pectoris lasting more than 20 minutes and ST-segment elevation $\geq 1 \mathrm{~mm}$ in multiple standard leads or $\geq 2 \mathrm{~mm}$ in multiple continuous pre-cordial leads, or when a presumable new left bundle branch block was present $(9,12)$. Important safety outcomes like re-infarction, stroke or transient ischemic attack and major bleeding were defined as previously reported (9). CS was defined as a systolic blood pressure $<100 \mathrm{mmHg}$ with pulse $>100$ beats/min combined with signs of peripheral or organ hypoperfusion, a need for inotropes, or mechanical circulatory support.

Recording of data was internet-based with a standard documentation form and concerned demographic data, as well as baseline characteristics, relevant time delays, peri-interventional treatment, reperfusion strategy, and angiographic success. Moreover, we recorded the use of mechanical circulatory support, although we did not distinguish between the types of support.

\section{Statistical analysis}

We present categorical variables with numbers and corresponding percentages of non-missing values. As for continuous variables, these are summarised with mean and standard deviation (SD) or with median and $25^{\text {th }}$ and $75^{\text {th }}$ percentile (inter-quartile range, IQR). As appropriate, Pearson chi-square, Fisher's exact, $t$-test, Mann-Whitney, or independent-samples median test was applied. We employed stratified (by PCI centre) multivariable logistic regression analysis, to adjust for associations of baseline characteristics, when comparing the effect of TRA with TFA on outcomes. The following potential confounders were pre-defined: age (in completed years), sex, CS, resuscitation (for the index event), previous MI, previous stroke, diabetes mellitus, atrial fibrillation, pre-treatment with $\mathrm{P}_{2} \mathrm{Y}_{12}$ inhibitors, glycoprotein 2b/3a inhibitors (GPIs), delay between pain onset and lesion cross (long vs. short; cut-off at 4 hours), TIMI non-CABGrelated major bleedings, and radial $v s$. femoral access site. We also assessed the impact of CS as a potential modifier of the effect of access site on the outcome by adding the interaction term in the regression model. The statistical analyses were performed in Stata/MP version 11.2.

\section{Etbical statement}

For the Registry we acted according to the Declaration of Helsinki (revised in 2013) and approval of the study protocol was attained from the Ethical Committee of the Medical University, Innsbruck (UN2467). Individual consent for this Registry analysis was waived.

\section{Results}

In total, for this study we included 9,980 patients: 4,498 patients (45\%) had a TRA and 5,482 (55\%) had a TFA. CS was more frequent in the femoral group $(n=663,12 \%)$ than in the radial group $(n=240,5 \%)$. Subsequently, the rate of TFA was $73 \%$ in patients with and $53 \%$ in patients without shock. Table 1 presents an overview with baseline characteristics and antithrombotic pre-treatment. Table 2 shows the procedural characteristics. While there was no difference in use of GPIs, treatment of bivalirudin use was more frequent in the femoral group. As for the 
Table 1 Baseline characteristics and antithrombotic treatment according to access

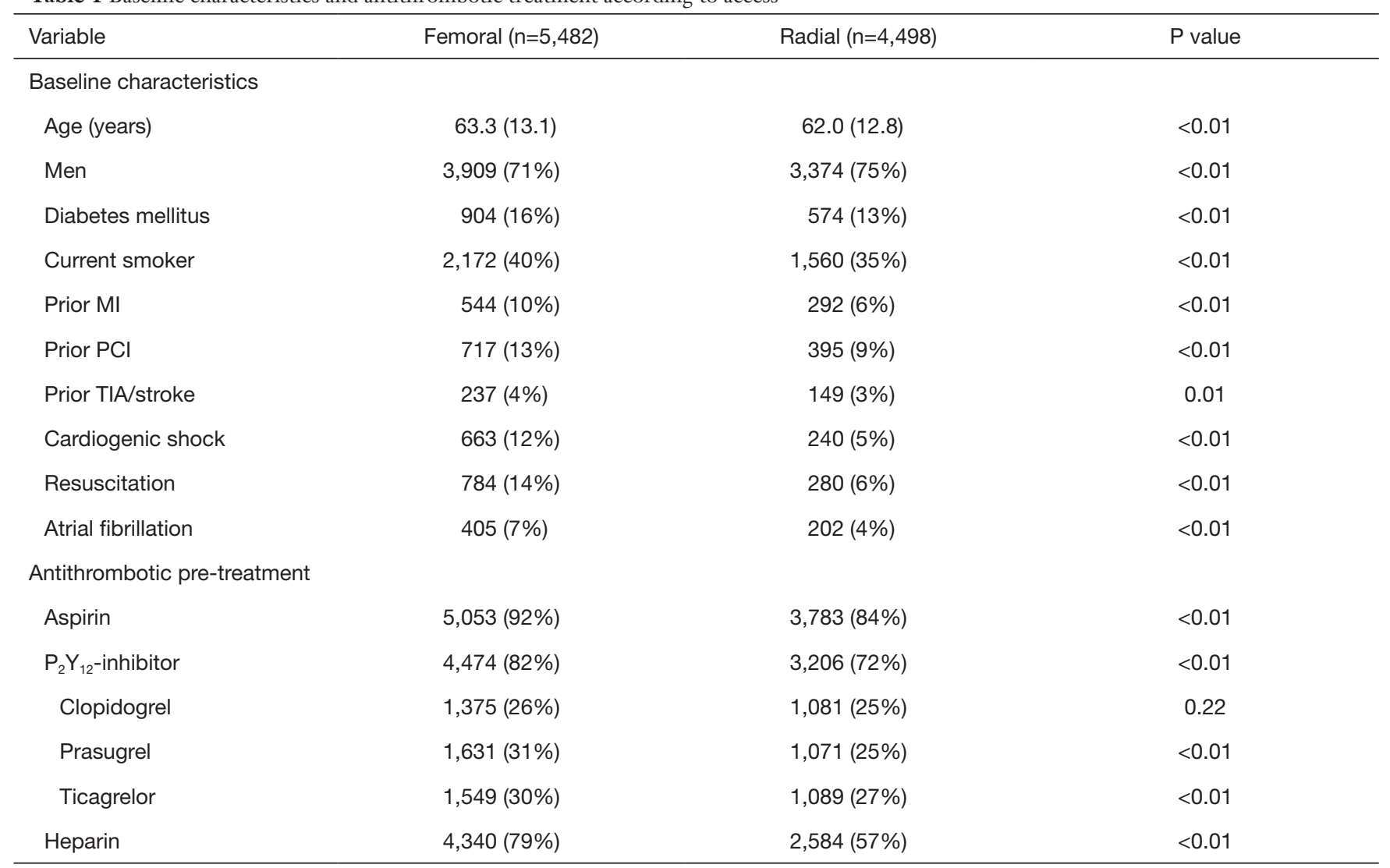

Age is presented with mean (standard deviation), categorical variables are presented with numbers (percentages) of non-missing values. $\mathrm{MI}$, myocardial infarction; $\mathrm{PCI}$, percutaneous coronary intervention; TIA, transient ischemic attack.

interventional management, there was a slight difference between the two groups regarding the type of intervention stents, but the angiographic success rates were similar. Hemodynamic support was more frequent in the patients receiving TFA, although it was very low in both treatment groups (Table 2).

Relevant time delays are listed in Table 3. The median delay from symptom onset to lesion crossing was longer in the radial group [radial 230 (IQR, 153 to 421) minutes vs. femoral 210 (IQR, 146 to 360) minutes]. However, there was no additional delay with radial access until lesion cross after arrival at the PCI center [radial 45 (IQR, 30 to 68) minutes vs. femoral 45 (IQR, 32 to 70) minutes] or the catheterisation laboratory [radial 23 (IQR, 18 to 30) minutes vs. femoral 23 (IQR, 17 to 30) minutes].

The choice of radial access site was associated with lower in-hospital mortality, MACE, and NACE in hemodynamically stable patients, but not so in patients with CS (Figure 1). TIMI-non-CABG related major bleeding was lower for TRA in stable patients $(0.5 \%$ vs. $0.2 \%, \mathrm{P}=0.02)$, but did not significantly differ in patients with CS $(2.0 \%$ vs. $0.8 \%, \mathrm{P}=0.38)$. Re-infarction rate was similar in stable $(0.8 \%$ vs. $0.8 \%, \mathrm{P}=0.81$ ) patients and there were slight differences in CS patients $(1.7 \%$ vs. $0.8 \%, \mathrm{P}=0.53)$. Analysis of TIA/ stroke showed comparable results with slightly higher rates for TFA in stable $(0.5 \%$ vs. $0.3 \%, \mathrm{P}=0.19)$ or $\mathrm{CS}$ patients ( $1.7 \%$ vs. $0.8 \%, \mathrm{P}=0.53$ ).

As shown in Table 4, radial access remained related to reduced in-hospital mortality when adjusting for confounders with multivariable regression, stratified by centre [odds ratio (OR) $0.57,95 \%$ confidence interval $(\mathrm{CI})$ : 0.43 to 0.75 ], with comparable effects for MACE (OR $0.60,95 \%$ CI: 0.47 to 0.78 ) and NACE (OR $0.59,95 \%$ CI: 0.46 to 0.75 ) (Table 5). The largest effects associated with outcome were CS, resuscitation, and bleeding (Tables 4,5). The interaction analysis demonstrated a modification of the effect of access site on in-hospital mortality in patients with CS (radial*shock, OR 1.78, 95\% CI: 1.07 to 2.96; Table 4). 
Table 2 Angiographic success and procedural characteristics according to access

\begin{tabular}{|c|c|c|c|}
\hline Variable & Femoral $(n=5,482)$ & Radial $(n=4,498)$ & $P$ value \\
\hline \multicolumn{4}{|l|}{ TIMI flow before intervention } \\
\hline $0-1$ & $3,910(77 \%)$ & $2,850(69 \%)$ & $<0.01^{*}$ \\
\hline II & $817(16 \%)$ & $734(18 \%)$ & \\
\hline \multicolumn{4}{|l|}{ TIMI flow after intervention } \\
\hline $0-1$ & $215(4 \%)$ & $169(4 \%)$ & $<0.01^{*}$ \\
\hline II & $294(6 \%)$ & $185(5 \%)$ & \\
\hline III & $4,453(89 \%)$ & $3,680(91 \%)$ & \\
\hline \multicolumn{4}{|c|}{ Peri-interventional antithrombotic treatment } \\
\hline Gp2b3a & $1,441(26 \%)$ & $1,173(26 \%)$ & 0.82 \\
\hline Bivalirudin & $490(9 \%)$ & $151(3 \%)$ & $<0.01$ \\
\hline \multicolumn{4}{|l|}{ Intervention } \\
\hline Bare metal stent & $581(11 \%)$ & $183(4 \%)$ & $<0.01^{*}$ \\
\hline Drug eluting stent & $4,159(81 \%)$ & $3,835(88 \%)$ & \\
\hline Bioabsorbable scaffold & $26(1 \%)$ & $11(0 \%)$ & \\
\hline Balloon angioplasty only & $254(5 \%)$ & 177 (4\%) & \\
\hline
\end{tabular}

*, these $\mathrm{P}$ values represent intra-category differences. Categorical variables are presented as numbers (percentages) of non-missing values.

Comparable, but not significant, effect modification was found for MACE and NACE in those patients (Table 5).

Using hemodynamically stable patients with TFA as the reference group (OR 1.00), radial access is associated with reduced mortality (OR $0.46,95 \%$ CI: 0.32 to 0.65 ) in stable patients, whereas no clear benefit was documented in patients with CS (radial OR 7.38, 95\% CI: 4.84 to 11.26 vs. femoral OR 9.06, $95 \%$ CI: 6.75 to 12.18 ).

\section{Discussion}

This study shows superiority of radial compared to TFA for in-hospital outcome in a large contemporary cohort of patients undergoing PPCI for acute STEMI. In particular, we detected a significant reduction of all-cause mortality, thereby affecting early MACE and NACE, in hemodynamically stable STEMI patients with TRA. In CS patients TFA had no worse effect on in-hospital outcome.

Radial access for PPCI today is the default access in many centres because of its favourable effect on bleeding (13), which in turn is associated with increased mortality. Recent randomised controlled trials have shown reduced mortality in patients undergoing PCI for acute coronary syndromes via TRA $(2,5,6,14)$. However, based on the recent SAFARI trial, the superiority of TRA over TFA in STEMI patients has been questioned (8).

Although the randomised controlled RIVAL trial failed to demonstrate a mortality benefit in the overall study cohort, in a pre-specified sub-group analysis containing 1,958 STEMI patients TRA was related to reduced 30-day 
Table 3 Treatment delays according to access

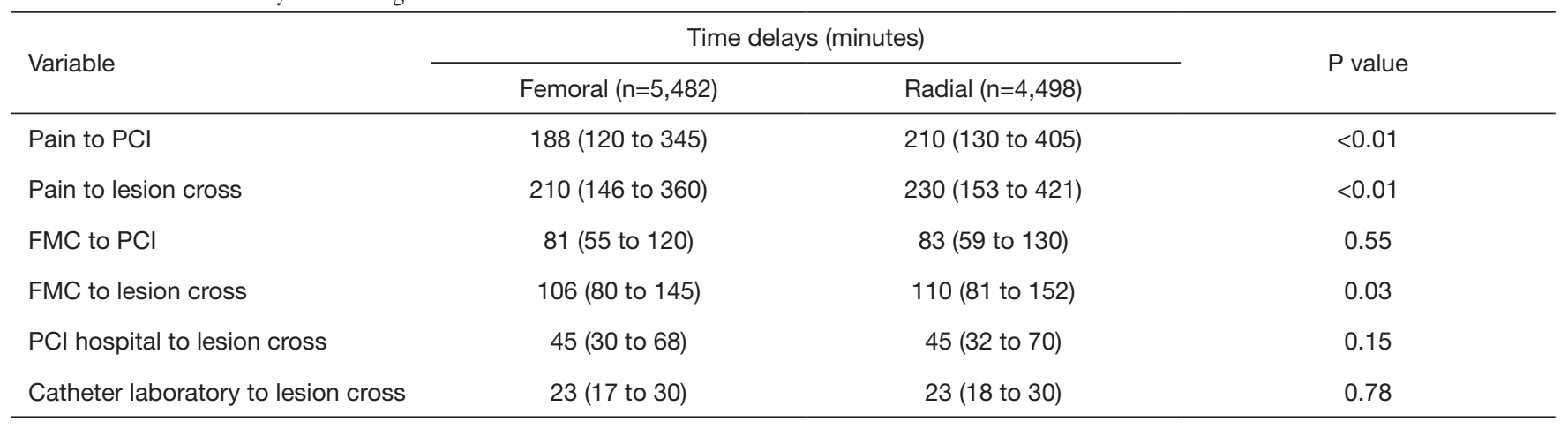

Values presented as median (inter quartile range). FMC, first medical contact; PCI percutaneous coronary intervention.
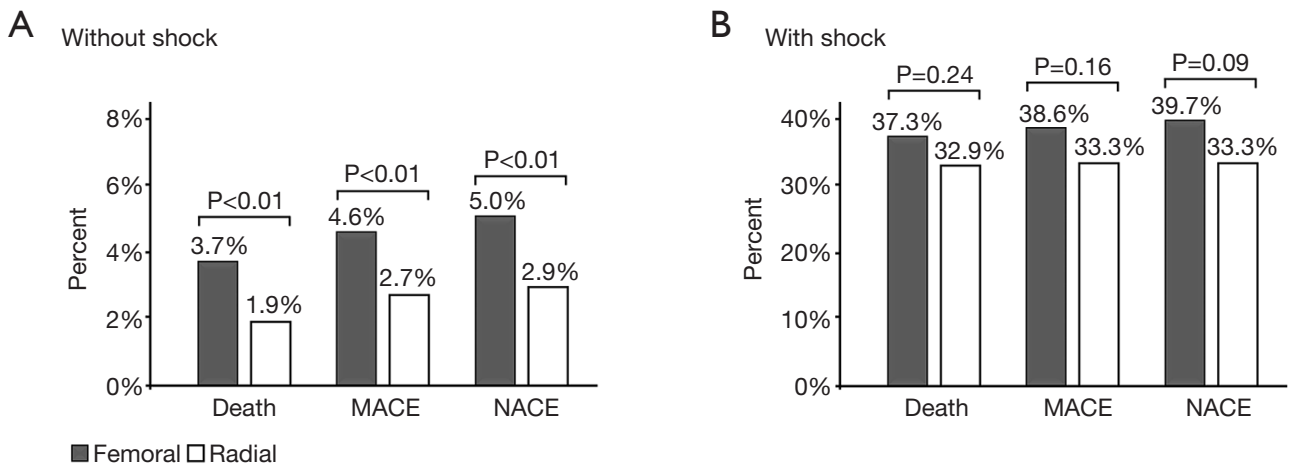

Figure 1 In-hospital outcomes according to access in patients without (A) and patients with cardiogenic shock (B). MACE, major adverse cardiac events; NACE, net adverse clinical events.

mortality (1.26\% vs. $3.19 \%, \mathrm{P}=0.006)(2,7)$. Additionally, the RIFLE-STEACS trial has shown reduced cardiac mortality at 30 days $(5.2 \%$ vs. $9.2 \%, \mathrm{P}=0.02)$ for TRA in STEMI patients (5). A beneficial effect on the composite ischemic endpoint as well as an improved net clinical benefit was demonstrated for TRA in the European MATRIX trial, including more than 8,000 patients $(4,6)$. However, there was no reduction in mortality in the STEMI cohort $(4,6)$.

Compared to these earlier studies, the recent SAFARI study neither showed superiority of TRA in PPCI in terms of mortality (TRA vs. TFA, $1.5 \%$ vs. $1.3 \%, \mathrm{P}=0.69$ ), nor a benefit in terms of bleeding ( $1.2 \%$ vs. $2.0 \%, \mathrm{P}=0.28)$ (8). GPIs have been linked to bleeding events and worse outcome in PPCI and were widely used in the early trials of TRA (69\% in RILFE STEACS, $45 \%$ in STEMI Radial) $(3,5)$. Following the guidelines, GPIs are less often used and account for $26 \%$ in our cohort. However, the low GPI rate of $6 \%$ in SAFARI and the excellent outcome might reflect a lower risk STEMI population, which may partially explain the lack of mortality benefit for TRA in that trial (8). Furthermore, in contrast to previous trials, bivalirudin, which is associated with a lower bleeding risk, was used in up to $80 \%$ of patients in the SAFARI trial $(8,15)$. This might have further attenuated possible beneficial effects of TRA in that trial, since we have previously shown an interaction of beneficial effects of TRA and bivalirudin (9).

Registry studies have also detected a possible beneficial effect of TRA in PPCI of hemodynamic stable patients $(16,17)$. The German ALKK registry showed that TRA was associated with an improved mortality (16). However, the rate of TRA was on average $14 \%$ and although adjusted for numerous covariates, a selection bias for lower risk patients in that early phase of TRA for PPCI (20082012) may be assumed. A more recent analysis from the NCDR Registry also showed a low rate of TRA (26\%) in STEMI with wide variations across operators and centres in the USA, thereby obviating reliable conclusions (17). Moreover, a prespecified subgroup analysis of RIVAL 
Table 4 In-hospital mortality after primary PCI in a multiple logistic regression analysis stratified by centre

\begin{tabular}{|c|c|c|c|c|}
\hline \multirow{3}{*}{ Variable } & \multicolumn{4}{|c|}{ Mortality } \\
\hline & \multicolumn{2}{|c|}{ Without interaction term } & \multicolumn{2}{|c|}{ With interaction term } \\
\hline & OR & $95 \% \mathrm{Cl}$ & OR & $95 \% \mathrm{Cl}$ \\
\hline Age & 1.06 & 1.05 to 1.07 & 1.06 & 1.05 to 1.07 \\
\hline Male sex & 1.09 & 0.85 to 1.40 & 1.08 & 0.84 to 1.38 \\
\hline Prior MI & 1.25 & 0.87 to 1.80 & 1.26 & 0.88 to 1.81 \\
\hline TIA/stroke & 1.74 & 1.16 to 2.61 & 1.71 & 1.14 to 2.57 \\
\hline Resuscitation & 3.37 & 2.54 to 4.49 & 3.39 & 2.55 to 4.50 \\
\hline Atrial fibrillation & 1.48 & 1.05 to 2.09 & 1.47 & 1.04 to 2.07 \\
\hline Pain to balloon & 1.50 & 1.18 to 1.89 & 1.50 & 1.19 to 1.90 \\
\hline Major bleeding & 6.23 & 2.95 to 13.13 & 6.13 & 2.90 to 12.94 \\
\hline Radial access & 0.57 & 0.43 to 0.75 & 0.46 & 0.32 to 0.65 \\
\hline Shock & 10.64 & 8.19 to 13.82 & 9.06 & 6.75 to 12.18 \\
\hline Radial*shock & - & - & 1.78 & 1.07 to 2.96 \\
\hline
\end{tabular}

Stratified by centre. Radial*shock represents the interaction term of effect modification. PCl, percutaneous coronary intervention; MI, myocardial infarction; TIA, transient ischemic attack; OR, odds ratio; $\mathrm{Cl}$, confidence interval.

showed improved outcomes in higher volume but not in lower volume radial centres (HR 0.49; 95\% CI: 0.28 to 0.87 ) demonstrating that centre procedural volume and expertise are important, particularly for radial percutaneous coronary intervention (18). The higher and more balanced rate of $45 \%$ TRA in our cohort may attenuate selection bias compared to earlier observational studies, which has been confirmed in a study of PCI for STEMI in the UK, where TRA has already become the default access site for PCI (mortality, OR 0.72, 95\% CI: 0.65 to 0.79$)(19)$. However, there are relevant differences between that study and ours. Notably, the UK study excluded crossover patients from their analysis and thus patients with primary access site failure (19). Additionally, they neither adjusted their results for time delays, nor for GPI use (19). Both GPI treatment and time delay are associated with higher mortality in our cohort (15). Our results are not contradictory to the two abovementioned studies, but add information from a more contemporary cohort with a strong signal of a beneficial effect of TRA in hemodynamically stable STEMI patients.
Considering TRA in patients with CS, most randomised trials excluded patients with CS or included only a few such patients $(3,6-8)$. Smaller, single centre case series and an analysis of patients with CS from the British Cardiovascular Intervention Database have reported a beneficial effect of TRA in CS (20-22). In the latter, TRA was associated with lower in-hospital mortality (HR 0.64, 95\% CI: 0.53 to 0.76) compared to TFA (21). In contrast, there was no clear beneficial effect of TRA in CS in our cohort. However, the two cohorts differ. Since the British Database included patients of all CS subsets and demonstrated that STEMI was an independent predictor of worse outcome, our subset of CS in PPCI might represent a higher risk patient group. Furthermore, they did not consider time delays in their analysis (21). Delayed reperfusion in myocardial infarction is associated with worse outcome, with 3.3 additional deaths per 100 PCI-treated patients being saved for every 10 minutes reduction of time from first medical contact to balloon inflation, according to the German FITT-STEMI registry (23).

The present study is a retrospective analysis of 
Table 5 MACE and NACE until discharge after primary PCI in multiple logistic regression analyses stratified by centre

\begin{tabular}{|c|c|c|c|c|c|c|c|c|}
\hline \multirow{2}{*}{ Variable } & \multicolumn{4}{|c|}{ MACE } & \multicolumn{4}{|c|}{ NACE } \\
\hline & OR & $95 \% \mathrm{Cl}$ & OR & $95 \% \mathrm{Cl}$ & OR & $95 \% \mathrm{Cl}$ & OR & $95 \% \mathrm{Cl}$ \\
\hline Age & 1.05 & 1.04 to 1.06 & 1.05 & 1.04 to 1.06 & 1.05 & 1.04 to 1.06 & 1.05 & 1.04 to 1.06 \\
\hline Male sex & 1.02 & 0.81 to 1.27 & 1.01 & 0.81 to 1.26 & 0.93 & 0.75 to 1.16 & 0.93 & 0.74 to 1.15 \\
\hline Prior MI & 1.25 & 0.90 to 1.74 & 1.25 & 0.90 to 1.74 & 1.26 & 0.91 to 1.74 & 1.26 & 0.92 to 1.74 \\
\hline TIA/stroke & 2.16 & 1.50 to 3.10 & 2.14 & 1.49 to 3.07 & 2.23 & 1.57 to 3.17 & 2.21 & 1.55 to 3.14 \\
\hline Resuscitation & 2.96 & 2.27 to 3.85 & 2.97 & 2.28 to 3.86 & 3.22 & 2.49 to 4.17 & 3.23 & 2.50 to 4.18 \\
\hline Atrial fibrillation & 1.54 & 1.12 to 2.11 & 1.53 & 1.12 to 2.09 & 1.51 & 1.11 to 2.06 & 1.50 & 1.11 to 2.05 \\
\hline Pain to balloon & 1.28 & 1.03 to 1.58 & 1.28 & 1.03 to 1.58 & 1.37 & 1.11 to 1.69 & 1.37 & 1.12 to 1.69 \\
\hline Major bleeding & 4.84 & 2.33 to 10.06 & 4.80 & 2.31 to 9.98 & - & - & - & - \\
\hline Radial access & 0.60 & 0.47 to 0.78 & 0.54 & 0.40 to 0.72 & 0.59 & 0.46 to 0.75 & 0.52 & 0.40 to 0.70 \\
\hline Shock & 8.30 & 6.50 to 10.59 & 7.44 & 5.64 to 9.81 & 7.91 & 6.22 to 10.05 & 7.13 & 5.44 to 9.35 \\
\hline Radial*shock & - & - & 1.47 & 0.92 to 2.36 & - & - & 1.45 & 0.91 to 2.31 \\
\hline
\end{tabular}

Stratified by centre. Radial*shock represents the interaction term of effect modification. MACE, major adverse cardiovascular events; NACE, net adverse clinical events; PCl, percutaneous coronary intervention; MI, myocardial infarction; TIA, transient ischemic attack; OR, odds ratio; $\mathrm{Cl}$, confidence interval.

observational data and has limitations, inherent to registries. First, imbalances in the treatment groups are unavoidable and failure to adjust for unidentified and unmeasured confounders may have influenced our observations. Second, the operators' choice for one of the two access sites and the operators' level of experience regarding one of the two approaches have not been recorded; this could have led to some imbalance between the treatment groups. Although stratifying for centre, we were not able to stratify for rates of TRA of individual operators. Third, rates of major bleeding were low and some events might have been missed due to underreporting. Fourth, information on some baseline characteristics was missing, whereas outcome data and the most relevant covariates were complete.

\section{Conclusions}

Our analysis in a large contemporary cohort of STEMI patients demonstrates that TRA is associated with improved outcomes after PPCI. This beneficial effect in hemodynamically stable patients is attenuated in patients with CS with otherwise no signs of worse outcome.

\section{Acknowledgments}

We thank all participating centres who contributed to this study.

Funding: The Austrian Acute PCI Registry (AAPCI) is supported by the Austrian Society of Cardiology.

\section{Footnote}

Reporting Checklist: The authors have completed the STROBE reporting checklist. Available at http://dx.doi. org/10.21037/cdt-20-977

Data Sharing Statement: Available at http://dx.doi. org/10.21037/cdt-20-977

Conflicts of Interest: All authors have completed the ICMJE uniform disclosure form (available at http://dx.doi. org/10.21037/cdt-20-977). The authors have no conflicts of 
interest to declare.

Ethical Statement: The authors are accountable for all aspects of the work in ensuring that questions related to the accuracy or integrity of any part of the work are appropriately investigated and resolved. The registry is conducted in accordance with the Declaration of Helsinki as revised in 2013 and the study protocol was approved by the Ethical Committee of the Medical University Innsbruck (UN2467). Individual consent for this registry analysis was waived.

Open Access Statement: This is an Open Access article distributed in accordance with the Creative Commons Attribution-NonCommercial-NoDerivs 4.0 International License (CC BY-NC-ND 4.0), which permits the noncommercial replication and distribution of the article with the strict proviso that no changes or edits are made and the original work is properly cited (including links to both the formal publication through the relevant DOI and the license). See: https://creativecommons.org/licenses/by-nc-nd/4.0/.

\section{References}

1. Ibanez B, James S, Agewall S, et al. 2017 ESC Guidelines for the management of acute myocardial infarction in patients presenting with ST-segment elevation: The Task Force for the management of acute myocardial infarction in patients presenting with ST-segment elevation of the European Society of Cardiology (ESC). Eur Heart J 2018;39:119-77.

2. Mehta SR, Jolly SS, Cairns J, et al. Effects of radial versus femoral artery access in patients with acute coronary syndromes with or without ST-segment elevation. J Am Coll Cardiol 2012;60:2490-9.

3. Bernat I, Horak D, Stasek J, et al. ST-segment elevation myocardial infarction treated by radial or femoral approach in a multicenter randomized clinical trial: the STEMIRADIAL trial. J Am Coll Cardiol 2014;63:964-72.

4. Vranckx P, Frigoli E, Rothenbuhler M, et al. Radial versus femoral access in patients with acute coronary syndromes with or without ST-segment elevation. Eur Heart J 2017;38:1069-80.

5. Romagnoli E, Biondi-Zoccai G, Sciahbasi A, et al. Radial versus femoral randomized investigation in ST-segment elevation acute coronary syndrome: the RIFLE-STEACS (Radial Versus Femoral Randomized Investigation in STElevation Acute Coronary Syndrome) study. J Am Coll
Cardiol 2012;60:2481-9.

6. Valgimigli M, Gagnor A, Calabro P, et al. Radial versus femoral access in patients with acute coronary syndromes undergoing invasive management: a randomised multicentre trial. Lancet 2015;385:2465-76.

7. Jolly SS, Yusuf S, Cairns J, et al. Radial versus femoral access for coronary angiography and intervention in patients with acute coronary syndromes (RIVAL): a randomised, parallel group, multicentre trial. Lancet 2011;377:1409-20.

8. Le May M, Wells G, So D, et al. Safety and Efficacy of Femoral Access vs Radial Access in ST-Segment Elevation Myocardial Infarction: The SAFARI-STEMI Randomized Clinical Trial. JAMA Cardiol 2020;5:126-34.

9. Hasun M, Dorler J, Edlinger M, et al. In-Hospital Outcome Comparing Bivalirudin to Heparin in RealWorld Primary Percutaneous Coronary Intervention. Am J Cardiol 2017;120:2135-40.

10. Dörler J, Alber HF, Altenberger J, et al. Primary percutaneous intervention of ST-elevation myocardial infarction in Austria: Results from the Austrian acute PCI registry 2005-2007. Wien Klin Wochenschr 2010;122:220-8.

11. Flynn MR, Barrett C, Cosio FG, et al. The Cardiology Audit and Registration Data Standards (CARDS), European data standards for clinical cardiology practice. Eur Heart J 2005;26:308-13.

12. Dörler J, Edlinger M, Alber HF, et al. Clopidogrel pretreatment is associated with reduced in-hospital mortality in primary percutaneous coronary intervention for acute ST-elevation myocardial infarction. Eur Heart J 2011;32:2954-61.

13. Jolly SS, Amlani S, Hamon M, et al. Radial versus femoral access for coronary angiography or intervention and the impact on major bleeding and ischemic events: a systematic review and meta-analysis of randomized trials. Am Heart $\mathbf{J}$ 2009;157:132-40.

14. Kwok CS, Rao SV, Myint PK, et al. Major bleeding after percutaneous coronary intervention and risk of subsequent mortality: a systematic review and meta-analysis. Open Heart 2014;1:e000021.

15. Stone GW, Witzenbichler B, Guagliumi G, et al. Bivalirudin during primary $\mathrm{PCI}$ in acute myocardial infarction. N Engl J Med 2008;358:2218-30.

16. Bauer T, Hochadel M, Brachmann J, et al. Use and outcome of radial versus femoral approach for primary PCI in patients with acute ST elevation myocardial infarction without cardiogenic shock: results from the 
ALKK PCI registry. Catheter Cardiovasc Interv 2015;86 Suppl 1:S8-14.

17. Valle JA, Kaltenbach LA, Bradley SM, et al. Variation in the Adoption of Transradial Access for ST-Segment Elevation Myocardial Infarction: Insights From the NCDR CathPCI Registry. JACC Cardiovasc Interv 2017;10:2242-54.

18. Jolly SS, Cairns J, Yusuf S, et al. Procedural volume and outcomes with radial or femoral access for coronary angiography and intervention. J Am Coll Cardiol 2014;63:954-63.

19. Ratib K, Mamas MA, Anderson SG, et al. Access site practice and procedural outcomes in relation to clinical presentation in 439,947 patients undergoing percutaneous coronary intervention in the United kingdom. JACC Cardiovasc Interv 2015;8:20-9.

20. Bernat I, Abdelaal E, Plourde G, et al. Early and late outcomes after primary percutaneous coronary

Cite this article as: Hasun M, Dörler J, Alber HF, Bauer A, Berger R, Christ G, Frick M, Hoppe UC, Huber K, Lamm G, Laßnig E, von Lewinski D, Rab A, Roithinger FX, Schuchlenz H, Siostrzonek P, Sipötz J, Stefenelli T, Steinwender C, Edlinger $M$, Weidinger $\mathrm{F}$; for the Austrian Acute PCI Investigators. Improved in-hospital outcome for radial access in a large contemporary cohort of primary percutaneous coronary intervention. Cardiovasc Diagn Ther 2021;11(3):726-735. doi: $10.21037 / \mathrm{cdt}-20-977$ intervention by radial or femoral approach in patients presenting in acute ST-elevation myocardial infarction and cardiogenic shock. Am Heart J 2013;165:338-43.

21. Mamas MA, Anderson SG, Ratib K, et al. Arterial access site utilization in cardiogenic shock in the United Kingdom: is radial access feasible? Am Heart J 2014;167:900-8.e1.

22. Rodriguez-Leor O, Fernandez-Nofrerias E, Carrillo X, et al. Transradial percutaneous coronary intervention in cardiogenic shock: a single-center experience. Am Heart J 2013;165:280-5.

23. Scholz KH, Maier SKG, Maier LS, et al. Impact of treatment delay on mortality in ST-segment elevation myocardial infarction (STEMI) patients presenting with and without haemodynamic instability: results from the German prospective, multicentre FITT-STEMI trial. Eur Heart J 2018;39:1065-74. 